\title{
INFLUENCE OF MATERIAL HARDNESS AND PARTICLE VELOCITY ON EROSIVE WEAR RATE
}

\author{
Ergin Kosa ${ }^{1}$, Ali Göksenli ${ }^{2, *}$ \\ ${ }^{1}$ Department of Mechanical Engineering, Beykent University, 34398, Istanbul, Turkey \\ ${ }^{2}$ Mechanical Engineering Faculty, Istanbul Technical University, 34437, Istanbul, Turkey \\ *Corresponding author: goksenli@itu.edu.tr
}

\begin{abstract}
Many parameters such as medium conditions and material properties are effective on erosiveabrasive wear rate. In this study, effect of particle impact velocity and hardness of material on wear rate and wear mechanism was investigated. All tests were carried out in 20\% sand-water mixture. Impact velocities of the particles were ranking between $2.04 \mathrm{~m} / \mathrm{s}$ and $4.76 \mathrm{~m} / \mathrm{s}$. Hardness values of St 37 and Ck 45 steels were changed by applying different heat treatments. After wear tests it was concluded that by an increase of impact velocity and decrease of material hardness, wear rate increased. This increase was by soft materials more dominant than by hard materials. After morphological investigations it is concluded that by an increase of material hardness, number and size of craters on the surface after erosion tests decreased. By using experimental test results, a new mathematical formulation was developed to emphasize the relation between impact velocity and material hardness on wear rate.
\end{abstract}

Keywords: Erosion, hardness, impact velocity, wear rate, mathematical model.

\section{INTRODUCTION}

Erosion wear is the removal of the material from the target after many cycles of impacting particle on the surface in a particle-liquid medium ${ }^{1-}$ ${ }^{4}$. This wear mechanism is active in pumps, pipes, valves and sharp corners in fluid transportation systems $^{5,6}$. To reduce erosion wear of the components, wear resistant coatings are performed by using different methods such as weld overlay diffusion $^{7}$, thermal spray ${ }^{8,9}$ or HVOF (high velocity oxy fuel) spray method ${ }^{10}$. Many parameters are effective on erosive wear rate such as liquid type, solid particle impact angle, velocity and energy, size and shape, solid particles concentration, hardness and toughness of the material ${ }^{7-13}$. Researchers have investigated the effect of different parameters on erosion wear. Fuyan et al. ${ }^{14}$, Abd-Elrhman et al. ${ }^{15}$, Patil et al. ${ }^{16}$ analyzed the effect of impact angle, Desale et al. ${ }^{17}$, Lynn et al. ${ }^{18}$, Liebhard et al. ${ }^{19}$ studied the effect of particle size , Dasgupta et al. ${ }^{20}$, Grewal et al. ${ }^{21}$ analyzed the effect of sand concentration, Levy et al. ${ }^{22}$ analyzed the effect of particle shape, Biswas et al. ${ }^{23}$, Franek et al. ${ }^{24}$ investigated the effect of particle impact energy, Sundararajan et al. ${ }^{25}$ analyzed the effect of slurry temperature and Gandhi et al. ${ }^{26}$ Okonkwo et al. ${ }^{27}$ Aquaro et al. ${ }^{28}$ studied the effect of impact velocity on wear rate and wear methodology. Limited studies were carried out to investigate the effect of material hardness on erosion wear rate and mechanism ${ }^{29-33}$. Most researchers carried out wear tests on ductile materials like aluminum or brass or they used very brittle materials like glass or ceramics. However, the materials used in valves, pipes and pumps are mostly alloyed steel, which are semi-ductile materials, indicating that previously performed erosion tests are not capable of emphasizing the wear rate amount used in these machine parts.

Some researchers established mathematical expressions to determine the relation between impact velocity $(\mathrm{v})$ and wear rate $\left(\mathrm{E}_{\mathrm{wear}}\right)$ by using experimental test results. During these analyses wear rate was expressed as;

$$
E_{\text {wear }}=K * v^{b}
$$

The power index of velocity (b) was, according to the test results carried out by different investigators, between 2 and $4^{34-36}$. The aim of the presented research was to investigate the effect of impact velocity and hardness of semi-hard materials having 245-880 Vickers Hardness Number [HVN] on wear rate and mechanism and to develop a mathematical formulation expressing the relation of hardness and impact velocity on wear rate by using experimental test results. The outcome of the study will provide a better understanding of the analysis of wear rate of semiductile materials used in machine parts like valves, pipes and pumps where erosion wear has a dominant effect.

Journal of Mechanical Engineering, Vol. ME 47, December 2017

Transaction of the Mechanical Engineering Division, The Institution of Engineers, Bangladesh 


\section{EXPERIMENTAL SET UP}

To determine the effect of different parameters on erosive-abrasive wear mechanism, a test tank was used. The set-up consists of three baffles, a propeller, two specimens and a holder. The propeller is fixed close to tank surface to prevent sand to accumulate at the bottom of the tank and to suspend the particles homogenously in the liquidsolid mixture. Baffles are added to prevent rotational movement of the hard particles. This will cause an upwards movement of the particles inside the liquid and a secondary flow, resulting in a homogenous liquid-solid mixture, which is desired for a realistic test analysis. The main dimensions and geometry of the test apparatus can be seen in figure 1.

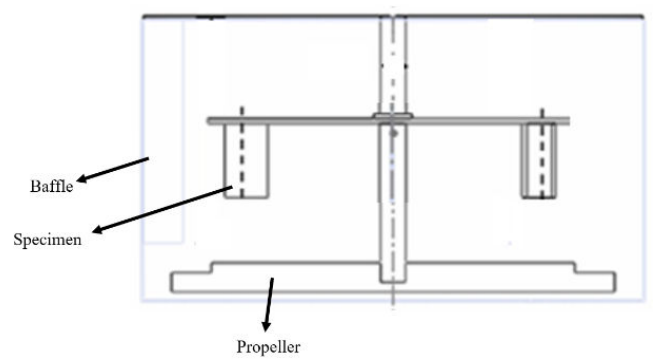

Figure 1. Main dimensions and geometry of the test apparatus

As wear specimens St 37 and $\mathrm{Ck} 45$ steels were used. The specimen sizes were $20 \times 35 \times 4 \mathrm{~mm}$. By each test, two samples were used. To change the hardness values of the steels, heat treatments were applied on both steels in an atmospheric furnace. Shimadzu microhardness tester with a Vickers indenter of $5 \mathrm{~N}$ was used to determine the microhardness (HVN) of the materials. The specimens were polished with up to \# 1000 emery paper and alumina, cleaned with tap water, rinsed in acetone and dried with hot air blower before and after each test. All tests were carried out in $20 \%$ weight concentration of hard particle quartz sandwater mixture. To eliminate the effect of rounding of sand particles and decreasing wear effect, the slurry was changed during the test ever one hour. Two class of sand were used having average particle diameters of $200 \mu \mathrm{m}$ and $650 \mu \mathrm{m}$. The mixture was rotated by using a drilling machine having potentiometer and electronic speed control. Particle impact velocity ranged from $2.04 \mathrm{~m} / \mathrm{s}$ (300 $\mathrm{rpm})$ to $4.76 \mathrm{~m} / \mathrm{s}(700 \mathrm{rpm})$ and particle impact angle was $90^{\circ}$. Mass loss of the wear specimens before and after four hours wear tests was measured by an electronic balance having least count of 0.1 mg.

\section{RESULTS}

To analyze the effect of hardness on wear rate four specimens were used. Material of the specimens were Ck 45 and St 37 steels. St 37 was non- heat treated $(245 \mathrm{HVN})$ and quenched (510 HVN), Ck steel was quenched (880 HVN) and quenched and annealed at $500{ }^{\circ} \mathrm{C}$ for 1 hour $(400$ HVN).

\section{Wear Rate}

To determine the effect of impact velocity and material hardness on wear rate, tests were applied on different steels by using hard particles having an average diameter of $200 \mu \mathrm{m}$. Impact velocity was calculated using the following equation;

$$
v=w * r
$$

$\mathrm{w}$ is the rotational speed [rot $/ \mathrm{min}]$ and $\mathrm{r}$ is the distance from the rotation axis $[\mathrm{m}]$, which is 65 $\mathrm{mm}$. The results can be seen in figure 2 .

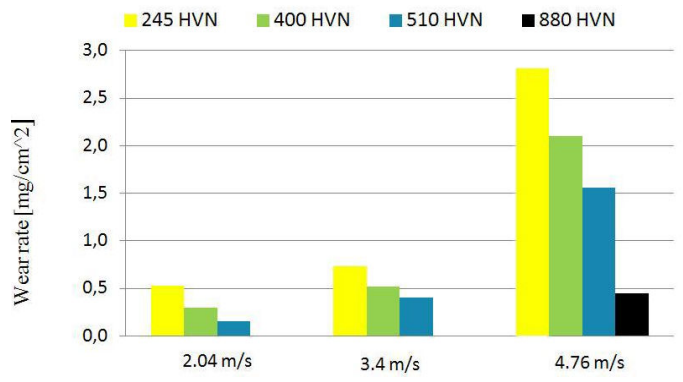

Figure 2. Effect of material hardness and impact velocity on wear rate (average sand diameter $=$ $200 \mu \mathrm{m})$

From figure 2 can be seen that by an increase of material hardness and decrease of impact velocity, wear rate decreases. Interesting was to observe that no wear occurred at materials having $880 \mathrm{HVN}$ at 2.04, 3.4 and $4.76 \mathrm{~m} / \mathrm{s}$ impact velocities, emphasizing a threshold impact velocity value by using average sand diameter of $200 \mu \mathrm{m}$ to proceed erosive wear for hard materials. To analyze wear rate of hard materials, average sand diameter was increased to $650 \mu \mathrm{m}$. Results can be seen in figure 3.

In figure 3 can be seen that by an increase of impact velocity of hard particle, wear rate increases. This increase is by soft materials more effective than hard materials, demonstrating that soft materials are more sensitive to change in impact velocities to erosive wear than hard materials. 


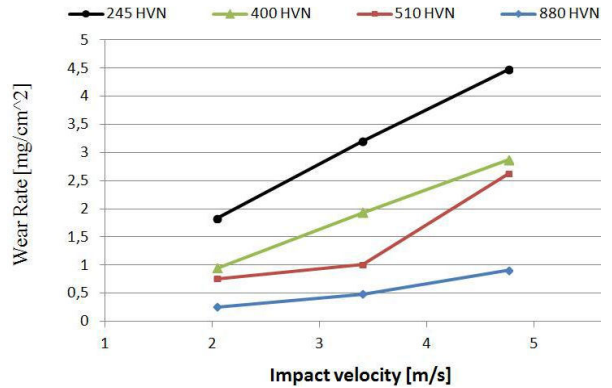

Figure 3. Effect of material hardness on wear rate at different impact velocities (average sand diameter $=650 \mu \mathrm{m})$

\section{Mathematical Model of Wear Rate}

From figures 2 and 3 can be seen that wear rate is affected by particle impact velocity. By an increase in impact velocity, wear rate increases. To determine the relation between wear rate $\left(\mathrm{E}_{\mathrm{wear}}\right)$ and impact velocity $(\mathrm{v})[\mathrm{m} / \mathrm{s}]$, an empirical correlation is expressed, as;

$$
E_{\text {wear }}=K * v^{b}
$$

By using previous experimental test results, the curve is fit to describe the wear according to impact velocity of the abrasive particle as can be seen in table 1 .

Table 1: Parameters of equation (3)

\begin{tabular}{|c|c|c|c|}
\hline HVN & K & B & $\begin{array}{c}\text { R-square } \\
\text { root }\end{array}$ \\
\hline 880 & 0.086 & 1.476 & 0.986 \\
\hline 510 & 0.248 & 1.395 & 0.837 \\
\hline 400 & 0.371 & 1.321 & 0.998 \\
\hline 245 & 0.860 & 1.062 & 0.999 \\
\hline
\end{tabular}

The amount of removal material on soft materials is much more than the hard materials as shown in figures 3 and 4 . The impact velocity becomes more dominant in wear rate especially of soft material having low hardness values. To determine the relation between wear rate $\left(\mathrm{E}_{\mathrm{wear}}\right)$ and material hardness $(\mathrm{H})[\mathrm{HVN}]$, an empirical correlation is expressed, by using previous experimental test results, as;

$$
E_{\text {wear }}=C * H^{a}
$$

At different hardness values, the curve is fit to describe the wear according to material hardness of the abrasive particle, which can be seen in table 2 .

Graphical view of the wear rate at an average particle size of $650 \mu \mathrm{m}$ can be seen in figure 4 .
Table 2: Mathematical parameters of equation (4)

\begin{tabular}{|c|c|c|c|}
\hline $\mathrm{V}[\mathrm{m} / \mathrm{s}]$ & $\mathrm{C}$ & $\mathrm{a}$ & $\begin{array}{c}\text { R-square } \\
\text { root }\end{array}$ \\
\hline 4.76 & 4211 & -1.22 & 0.929 \\
\hline 3.40 & 14413 & -1.51 & 0.977 \\
\hline 2.04 & 8308 & -1.51 & 0.980 \\
\hline
\end{tabular}

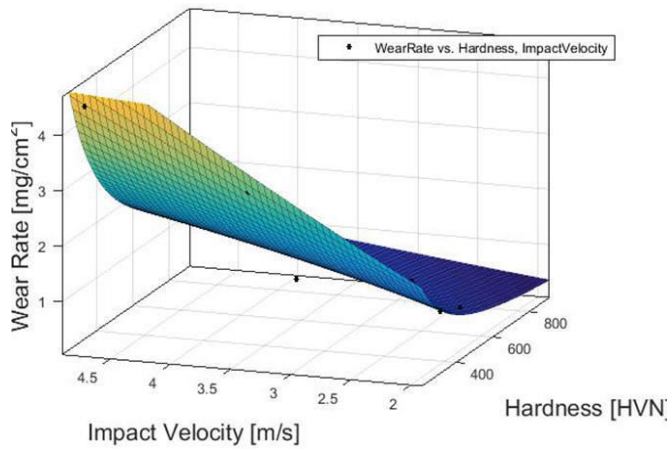

Figure 4. Effect of impact velocity and hardness on wear rate

To analyze the effect of particle impact velocity and material hardness on wear rate, results of table 2 and 3 are used. The mathematical expression can be determined as follows;

$$
E_{\text {wear }}(H, v)=a * H^{n} * v^{k}
$$

To determine the coefficients $\mathrm{a}, \mathrm{n}$ and $\mathrm{k}$, MATLAB ${ }^{\circledR}$ program was used. The mathematical formula for calculating wear rate, considering hardness of the metallic material and impact velocity can be expressed as;

$$
E_{\text {wear }}(H, v)=310.3 * H^{-1.104} * v^{1.208}
$$

Coefficients are $\% 95$ confidence bounce and Rsquare root is 0.962 . It must be considered that this formula is only valid for impact particles with an average diameter of $650 \mu \mathrm{m}$.

\section{Wear Surface}

To examine the wear mechanism at metallic material having different hardness value, worn surfaces were analyzed by using Scanning Electron Microscopy (SEM). Impact of erosive particles caused removal of material and formation of craters, which can be seen in figures 5-8. 


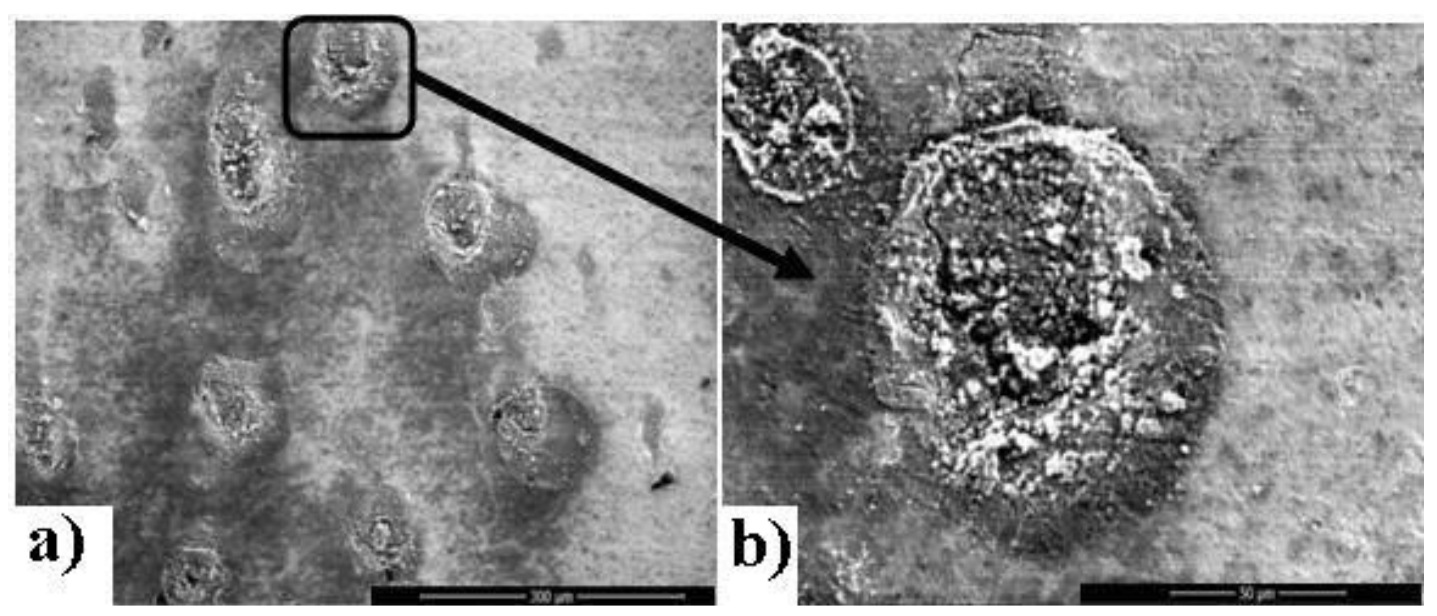

Figure 5. SEM observations of non-heat treated St 37 (245 HVN) samples (a) x500, (b) x2000
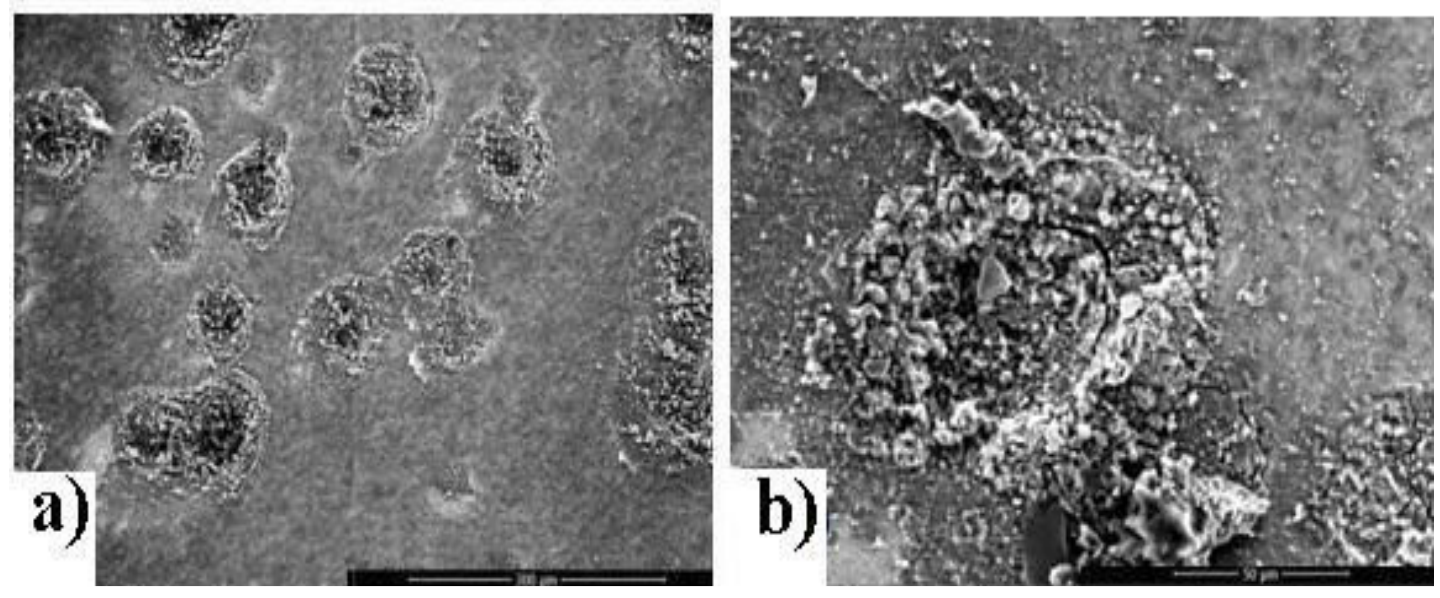

Figure 6. SEM observations of quenched and heat treated Ck (400 HVN) Ck 45 samples (a) x500, (b) $\times 2000$

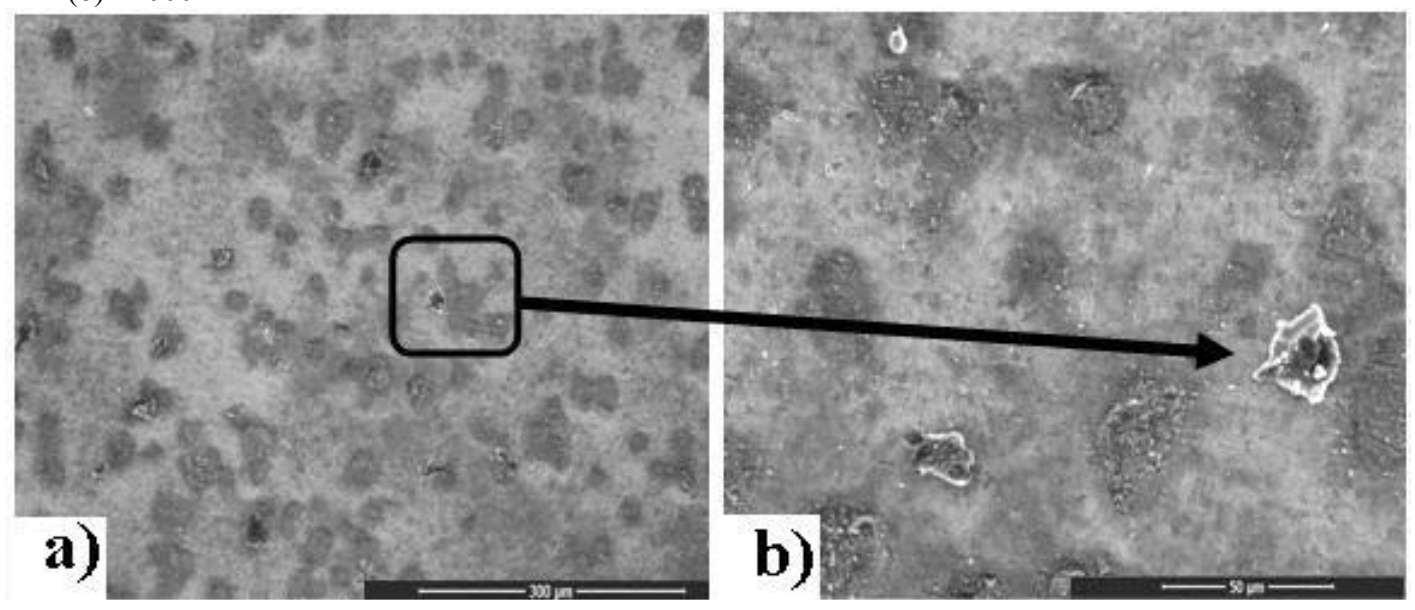

Figure 7. SEM observations of quenched St 37 (510 HVN) samples (a) x500, (b) x2000

Journal of Mechanical Engineering, Vol. ME 47, December 2017

Transaction of the Mechanical Engineering Division, The Institution of Engineers, Bangladesh 

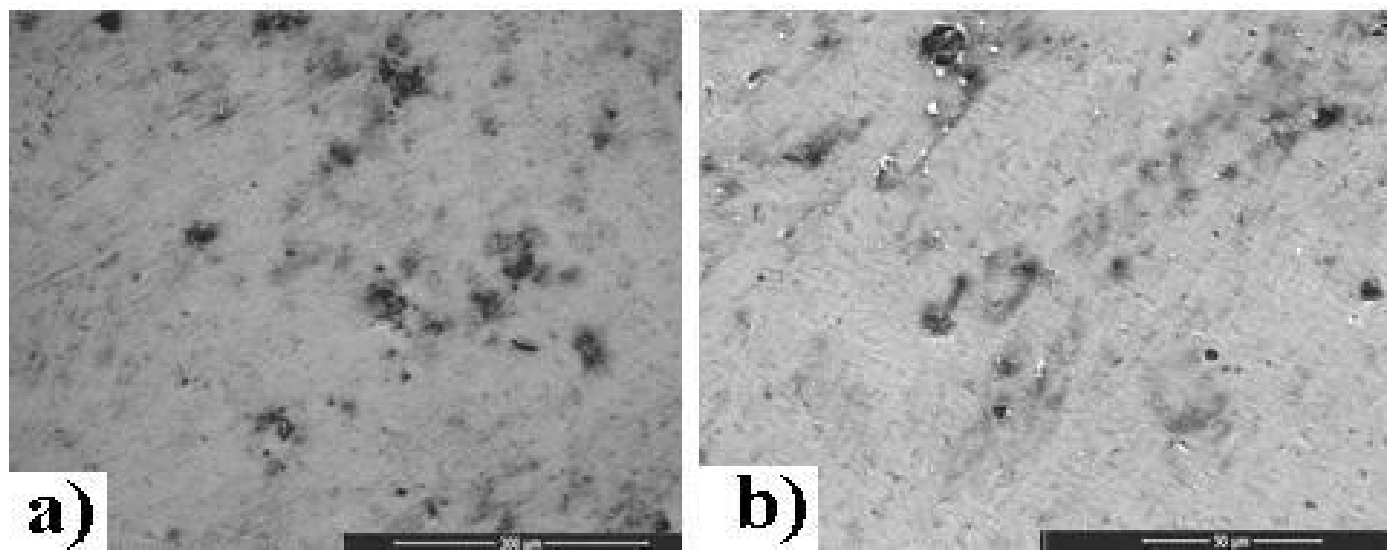

Figure 8. SEM observations of quenched Ck (880 HVN) Ck 45 samples (a) x500, (b) x2000

From figures 5-8, SEM images of worn surfaces of soft and hard materials can be seen. After analysis of figures $5-8$, it is concluded that by an increase of material hardness, number of craters and pits decreased. This demonstrates that by increase of material hardness, the mass loss of the steel decreases and tends to be more resistant to erosive wear. Also the depth of the craters in hard materials is less compared with soft specimens. The average diameters of the craters in hard materials are 20-25 $\mu \mathrm{m}$ and about $150-180 \mu \mathrm{m}$ in soft materials. Partly ploughing worn mechanism was detected in worn surface of soft materials. Deformation mechanism was identified in worn surface of hard materials. No chip formation was observed in soft and hard materials.

\section{CONCLUSIONS}

The aim of the presented research was to study the effect of particle impact velocity and hardness of the material on wear rate by using quartz sand as abrasive particle. Impact velocities of the particles were between $2.04 \mathrm{~m} / \mathrm{s}-4.76 \mathrm{~m} / \mathrm{s}$. To analyze the effect of material hardness, St 37 and Ck 45 steels were used by applying different heat treatments between 245-880 HVN. After wear tests it was concluded that by an increase of impact velocity and decrease of material hardness, wear rate increased. This increase was by soft materials more efficient than hard materials, demonstrating that soft materials were more sensitive to change in impact velocities than hard materials. No wear was observed at hard materials by $200 \mu \mathrm{m}$ average diameter under a threshold impact velocity. By increase of material hardness, amount and depth of craters decreased. Ploughing worn mechanism was detected in worn surface of soft materials and deformation mechanism in worn surface of hard materials which is typical at high impact angles. By using experimental results, a new

mathematical expression was developed to emphasize the relation between impact velocity and material hardness on wear rate. This study will be developed by analyzing the effect of hard particle size on wear rate and to express a new mathematical formulation considering material hardness, impact velocity and particle average diameter.

\section{ACKNOWLEDGEMENT}

This study was supported by Istanbul Technical University Scientific Research Project. The authors would like to thank Muhammed Bekin for his contribution by performing SEM analysis.

\section{REFERENCES}

1. Karl-Heinz, Z.G., 1987, “Williams J. Microstructure and Wear of Materials," Tribology Series. 10 Elsevier, 1987.

2. Abd-Elrhman, Y.M., Abouel-Kasem, A., Ahmed, S.M. \& Emara, K.M., 2012, "Stepwise Erosion as a method for investigating the wear mechanisms at different impact angles in Slurry erosion," Journal of Engineering Science, 40, pp. 1055-1074.

3. Randall, S.L., Kien, K. \& Hector, M.C.I., 1991, "On the particle size effect in slurry erosion,", Wear, 149, pp. 55-71.

4. Williams, A., 2005, "Wear and wear particles some Fundamentals," Tribology International, 38, pp. 863-870.

5. Yildizli, K., Eroglu, M. \& Karamis, K.M., 2005, "Erosive Wear Behaviour of Hardfacing 
Austenitic Manganese Deposit," Tribology in Industry, 27, pp. 15-21.

6. Franek, F., Badisch, E. \& Kirchgassner, M., 2009, "Advanced Methods for Characterisation of Abrasion/Erosion Resistance of Wear Protection Materials," FME Transactions, 37, pp. 61-70.

7. Hejwowski, T., 2009, "Erosive and abrasive wear resistance of overlay coatings," Vacuum, 83, pp. 166-170.

8. Barbezat, G., 2005, “Advanced thermal spray technology and coating for lightweight engine blocks for the automotive industry," Surface and Coatings Technology, 200, pp. 1990-1993.

9. Dorfman, M., 2002, Wear-Resistant Thermal Spray Coatings," Sulzer Technology Review, 2, pp. 14-17.

10. Rogers, P.M., Hutchings, I.M. \& Little, J.A., 1995, "Coatings and surface treatments for protection against low-velocity erosion-corrosion in fluidized beds," Wear, 186-187, pp. 238-246.

11. Clark, H.M. \& Hartwich, R.B., 2001, “A reexamination of the 'particle size effect' in slurry erosion," Wear, 248, pp. 147-161.

12. Saraswathi, Y.L., Das, S. \& Mondal, D.P., 2006, "Influence of microstructure and experimental parameters on the erosion-corrosion behavior of Al alloy composites," Material Science and Engineering A, 425, pp. 244-254.

13. Tabakoff, W., 1999, "Erosion resistance of superalloys and different coatings exposed to particulate flows at high temperature," Surface and Coatings Technology, 120-121, pp. 542-547.

14. Fuyan, L. \& Hesheng, S., 1991, "The effect of impingement angle on slurry erosion," Wear, 141, pp. 279-289.

15. Abd-Elrhman, Y.M., Abouel-Kasem, A., Emara, K.M. \& Ahmed, S.M., 2013, "Effect of Impact Angle on Slurry Erosion Behaviour and Mechanisms of Carburized AISI 5117 Steel," Journal of Engineering Science, 41, pp. 137-157. 16. Patil, M.S., Deore, E.K., Jahagirdar, R.S. \& Patil, S.V., 2011, "Study of the Parameters Affecting Erosion Wear of Soft Material in SolidLiquid Mixture," Proceedings of the World Congress on Engineering. Vol III, London, U.K. 17. Desale, G.R., Gandhi, B.K. \& Jain, S.C., 2006, "Effect of erodent properties on erosion wear of soft type materials," Wear, 261, pp. 914-921.

18. Lynn, S., Kien, K. \& Hector, M.C.I., "On the particle size effect in slurry erosion," Wear, 149, pp. 55-71.

19. Liebhard, M. \& Levy, A., 1991, "The effect of erodent particle characteristics erosion of metals," Wear, 151, pp. 381-390.

20. Dasgupta, R., Prasad, B.K., Jha, A.K., Modi, O.P., Das, S. \& Yegneswaran, A.H., 1998, "Effects of Sand Concentration on Slurry Erosion Steels," Material Transaction, 39, pp. 1185-1190.

21. Singh, H., Harpreet, G., Arora, S., Sing, H. \& Mukherjee, S., 2013, "Slurry Erosion of Thermal Spray Coatings: Effect of Sand Concentration," Procedia Engineering, 68, pp. 484-490.

22. Levy, A., 1995, "Solid Particle Erosion and Erosion-corrosion of Materials," ASM International, Ohio.

23. Biswas, S., Cenna, A., Williams, K. \& Jones, M., 2014, "Subsurface behavior of soft material by particle impacts and its influence on wear mechanism," Procedia Engineering, 90, pp. 160 165.

24. Franek, F., Badisch, E. \& Kirchgassner, M., 2009, "Advanced Methods for Characterisation of Abrasion/Erosion Resistance of Wear Protection Materials," FME Transactions, 37, pp. 61-70.

25. Sundararajan, G. \& Roy, A., 1997, "Solid particle erosion behaviour of metallic materials at room and elevated temperatures," Tribology International, 30, pp.339-359.

26. Gandhi, B.K., Singh, S.N. \& Seshadri, V., 1999, "Study of the parametric dependence of erosion wear for the parallel flow of solid-liquid mixtures," Tribology International, 32, pp. 275282.

27. Okonkwo, P.C., Mohamed, A.M.A. \& Ahmed, E., 2015, "Influence of particle velocities and impact angles on the erosion mechanisms of AISI 1018 steel," Advanced Material Letter, 6, pp. 653659.

28. Aquaro, D., 2010, "Impact of Solid Particulate on Hard Materials," Journal of Mechanical Engineering, 56, pp. 275-283.

29. Oka, Y.I., Olmogi, H., Hosokawa, T. \& Matsumura, M., 1997, "The impact angle dependence of erosion damage caused by solid particle impact," Wear, 203-204, pp. 573-579.

30. Karabay, S., 2014, "The Effect of Heat Treatments on the Solid-Particle Erosion Behavior of the Aluminum Alloy AA2014," Materials and Technology, 48, pp. 141-147.

31. Sapate, S.G. \& Rao, A.V.R., 2002, "Effect of material hardness on erosive wear behavior of some weld-deposited alloys," Material and Manufacturing. Process, 17, pp. 187-198.

32. Agunsoyea, J.O. \& Ayeni, A.A., 2012, "Effect of Heat Treatment on the Abrasive Wear Behavior of High Chromium Iron under Dry Sliding Condition," Tribology in Industry, 34, pp. 82-91.

33. Clark, H. \& Wong, K.K., 1995, "Impact angle, particle energy and mass loss in erosion by dilute slurries," Wear, 186-187, pp. 454-464.

34. Jha, A.K., Batham, R., Ahmed, M., Majumder, A.K., Modi, O.P., Chaturvedi, S. \& Gupta, A.K., 
2011, "Effect of impinging angle and rotating speed on erosion behavior of aluminum," Transaction of Nonferrous Metals Social China, 21, pp. 32-38.

35. Patil, M.S., Deore, E.R., Jahagirdar, R.S. \& Patil, S.V., 2011, "Study of the Parameters Affecting Erosion Wear of Soft Material in SolidLiquid Mixture," Proceedings of the World Congress on EngVol III WCE July 6 - 8, London, U.K.

36. Gupta, R., Singh, S.N. \& Sehadri, V., 1995, "Prediction of uneven wear in a slurry pipeline on the basis of measurements in a pot tester," Wear, 184 , pp. $169-178$.

Journal of Mechanical Engineering, Vol. ME 47, December 2017 Transaction of the Mechanical Engineering Division, The Institution of Engineers, Bangladesh 